\title{
Film condensation on non-isothermal vertical plates
}

\author{
H. J. H. BROUWERS \\ Akzo Research Laboratories, Fibres and Polymers Division, Department of \\ Mechanical Research, Velperweg 76, 6824 BM Arnhem, The Netherlands
}

(Received 6 November 1987 and in final form 7 July 1988)

\begin{abstract}
An analytical study is presented of the condensation of a pure saturated vapour on a cooled channel plate, including the interaction between the cooling liquid, the condensate and the vapour. The governing equations of co-, counter- and cross-current condensation are derived, set dimensionless and solved in closed form. The resulting implicit expressions are evaluated numerically by iteration. In this way results for condensation heat transfer are obtained for a broad range of the characteristic dimensionless numbers of the process: the McAdam number and the number of transfer units. Furthermore, using asymptotic methods, a simple approximate expression is derived that is suitable for engineering end purposes.
\end{abstract}

\section{INTRODUCTION}

IN THE recently developed plastic gas-liquid heat exchangers channel plates are applied as heat transfer surfaces. These plates are made of polyvinylidene fluoride (PVDF) by spinning or extrusion. In these plates small channels have been provided through which there flows a cooling liquid, e.g. water. Because the walls of the channels are very thin, the heat transfer coefficient is very good compared with that of conventional metal heat exchangers, although the thermal conductivity of PVDF is only $0.19 \mathrm{~W} \mathrm{~m}^{-1} \mathrm{~K}^{-1}$ (Fig. 1).

As a result of the application of this polymer, the maximum operational temperature is $150^{\circ} \mathrm{C}$. The heat exchangers are suited for condensing vapours with a dew point below this threshold temperature, especially corrosive and poisonous vapours, such as toluene, benzene, chloroethane, several acids and, of course, steam.

Condensation of pure saturated vapours on vertical flat plates has often been examined in the past. Several extensions and improvements have been proposed to the original solution of Nusselt [1]. Extensions include inertia [2], heat capacity of the condensate $[2,3]$ and drag of the vapour $[4,5]$.

However, the condensation problems analysed thus far have - to the author's knowledge - been limited to isothermal plates. Temperature rises of the cooling liquid as a result of liberated latent heat are neglected. Such temperature rises and their interaction with the condensation process are considered to be important and typical of channel plates.

In this paper condensation on channel plates is studied in some detail. Taken into account are conduction and convection in the plate, heat transfer in the condensate, and their interactions.

Three types of configuration are examined, namely the flow of the condensate under the action of gravity in the direction of the liquid flow, called co-current, in the opposite direction, called counter-current and perpendicular to the liquid flow, called cross-current condensation. It is assumed that both the liquid and condensate flow are unmixed and that the condensate forms a laminar, non-rippling film on the plate. The physical properties of the liquid and the condensate are assumed to be constant.

The governing equations of the processes will be derived, set dimensionless, and analytical solutions of these non-linear equations will be provided. It is shown that the processes are governed by two dimensionless numbers: the McAdam number $A d$, and the number of transfer units $N T U$. Based on the analytical solutions and an asymptotic analysis, there is derived an approximate result that is compact and accurate for most practical values of the dimensionless numbers characterizing the processes.

\section{FORMULATION OF BASIC EQUATIONS}

First, the equations of the cross-current condensation process will be mathematically formulated, because this is the most general case. The equations of the other situations can easily be derived from the equations of this process.

The liquid flowing through the channels has an inlet temperature $T_{\text {in }}$, which is lower than the saturation temperature $T_{\text {sat }}$ of the vapour (Fig. 2). For the channel plate, an energy balance for an element $\mathrm{d} x \mathrm{~d} z$ involves conduction and convection heat flows within the plate and an inflow of heat from the condensate. This energy balance can be written as

$$
\frac{w_{1} c_{p 1}}{B} \frac{\partial T}{\partial z}=h_{\mathrm{t}}\left(T_{\mathrm{sat}}-T\right)
$$

where $h_{\mathrm{t}}$ is defined as the overall heat transfer co- 


\section{NOMENCLATURE}

$a \quad$ wall thickness [m]

Ad McAdam number, defined by equation (33) or (49)

$B \quad$ plate width [m]

$c_{p} \quad$ specific heat $\left[\mathrm{J} \mathrm{kg}^{-1} \mathrm{~K}^{-1}\right]$

$D_{\mathrm{h}} \quad$ hydraulic diameter of a channel [m]

$g \quad$ acceleration due to gravity $\left[\mathrm{m} \mathrm{s}^{-2}\right]$

$h_{\mathrm{c}}$ heat transfer coefficient of the condensate, defined by equation (3) [W m ${ }^{-2} \mathrm{~K}^{-1}$ ]

$h_{1} \quad$ mean heat transfer coefficient of the liquid, defined by equation (5) [W $\mathrm{m}^{-2} \mathrm{~K}^{-1}$ ]

$h_{\mathrm{p}} \quad$ heat transfer coefficient of the channel walls, defined by equation (4)

[W $\mathrm{m}^{-2} \mathrm{~K}^{-1}$ ]

$h_{\mathrm{pl}} \quad$ heat transfer coefficient of the plate, defined by equation (30) [ $\mathrm{W} \mathrm{m}^{-2} \mathrm{~K}^{-1}$ ]

$h_{\mathrm{t}} \quad$ total heat transfer coefficient, defined by equation (2) [ $\left.\mathrm{W} \mathrm{m}^{-2} \mathrm{~K}^{-1}\right]$

$H_{\mathrm{fg}} \quad$ latent heat of condensation [ $\left.\mathrm{J} \mathrm{kg}^{-1}\right]$

$k$ thermal conductivity [ $\mathrm{W} \mathrm{m}^{-1} \mathrm{~K}^{-1}$ ]

$K u \quad$ Kutateladze number, $c_{p c}\left(T_{\mathrm{sat}}-T_{\mathrm{in}}\right) / H_{\mathrm{fg}}$

$L \quad$ plate length [m]

$\dot{m} \quad$ local mass flux $\left[\mathrm{kg} \mathrm{m}^{-2} \mathrm{~s}^{-1}\right]$

$\dot{M} \quad$ total mass flux $\left[\mathrm{kg} \mathrm{s}^{-1}\right]$

NTU number of transfer units, defined by equation (32)

$\mathrm{Nu} \quad$ mean Nusselt number, $h_{1} D_{\mathrm{h}} / k_{1}$

$p$ dimensionless parameter defined by equation (38)

$\operatorname{Pr} \quad$ Prandtl number, $\eta_{c} c_{p c} / k_{c}$

$q \quad$ dimensionless parameter defined by equation (46)
$Q \quad$ dimensionless heat flux, defined by equation (63)

$T$ temperature of the liquid $[\mathrm{K}]$

$T_{\text {in }} \quad$ entry temperature of the liquid $[\mathrm{K}]$

$T_{\text {out }} \quad$ take-off temperature of the liquid [K]

$T_{\text {sat }} \quad$ saturation temperature of the vapour $[\mathrm{K}]$

$u \quad$ component of velocity in the $x$-direction $\left[\mathrm{m} \mathrm{s}^{-1}\right]$

$v \quad$ component of velocity in the $y$-direction $\left[\mathrm{m} \mathrm{s}^{-1}\right]$

$w_{1} \quad$ liquid mass flow $\left[\mathrm{kg} \mathrm{s}^{-1}\right]$

$x, y, z$ coordinates $[\mathrm{m}]$

$X \quad x / B$

$Z \quad z / L$.

\section{Greek symbols}

\begin{tabular}{|c|c|}
\hline$\delta$ & film thickness of the condensate $[\mathrm{m}]$ \\
\hline$\Delta$ & $h_{\mathrm{p} /} / h_{\mathrm{c}}$ \\
\hline & $\begin{array}{l}\text { perturbation quantity, defined by } \\
\text { equations (67) and (73) }\end{array}$ \\
\hline & dynamic viscosity $\left[\mathrm{N} \mathrm{m}^{-1} \mathrm{~s}^{-1}\right]$ \\
\hline$\Theta$ & $\left(T_{\text {sat }}-T\right) /\left(T_{\text {sat }}-T_{\text {in }}\right)$ \\
\hline$\Theta_{\text {out }}$ & $\begin{array}{l}\left(T_{\text {sat }}-T_{\text {out }}\right) /\left(T_{\text {sat }}-T_{\text {in }}\right) \\
\text { mean dimensionless temperature, } \\
\text { defined by equation (54) }\end{array}$ \\
\hline & specific density $\left[\mathrm{kg} \mathrm{m}^{-3}\right]$. \\
\hline
\end{tabular}

Subscripts

c condensate

1 liquid

$\mathrm{p} \quad$ plate wall

v vapour. efficient of the condensate and the plate, $B$ the plate width, $w_{1}$ the liquid mass flow, $T(x, y)$ the temperature of the liquid and $c_{p 1}$ the isobaric specific heat of the liquid. The heat transfer coefficient $h_{\mathrm{t}}$ consists of three parts

$$
\frac{1}{h_{\mathrm{l}}}=\frac{1}{h_{\mathrm{c}}}+\frac{1}{h_{\mathrm{p}}}+\frac{1}{h_{1}} .
$$

The heat transfer coefficient $h_{\mathrm{c}}$ of the condensate is a function of both $x$ and $z$

$$
h_{\mathrm{c}}=\frac{2 k_{\mathrm{c}}}{\delta}
$$

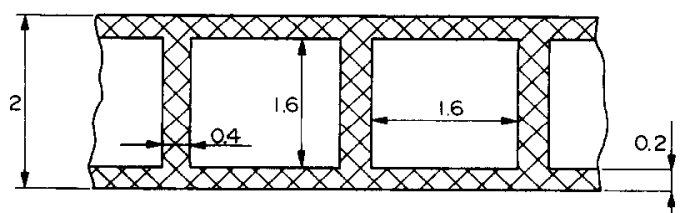

FIG. 1. Channel plate (sizes in mm). where $k_{\mathrm{c}}$ is the thermal conductivity of the condensate and $\delta(x, z)$ the film thickness.

The contribution of subcooling of the condensate is neglected because the Kutateladze number $K u$ of the relevant condensates is small. In refs. $[2,3]$ it has been demonstrated that for small Kutateladze numbers convection plays a secondary role because the film is so thin. The heat transfer coefficient $h_{\mathrm{p}}$ in

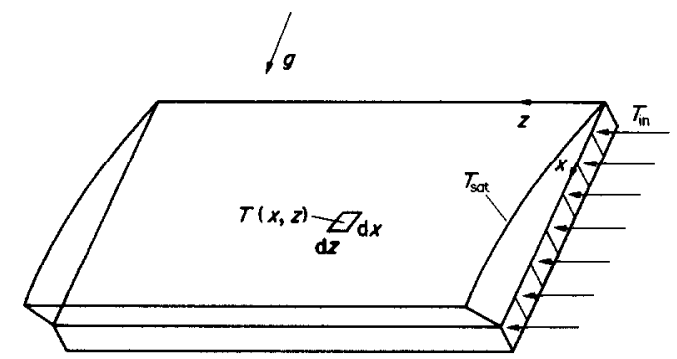

FIG. 2. Cross-current condensation process. 
equation (2) stands for the conduction through the walls of the plate

$$
h_{\mathrm{p}}=\frac{2 k_{\mathrm{p}}}{a}
$$

where $k_{\mathrm{p}}$ is the thermal conductivity of the plate material and $a$ the wall thickness. The forced convection heat transfer coefficient $h_{1}$ in equation (2) takes the convective heat transfer in the channels into account

$$
h_{1}=\frac{2 N u k_{1}}{D_{\mathrm{h}}}
$$

where $k_{1}$ is the thermal conductivity of the liquid and $D_{\mathrm{h}}$ the hydraulic diameter of the square channel, defined as four times the cross-sectional area divided by the perimeter. The Nusselt number $\mathrm{Nu}$ depends on $z$ because of hydraulic and thermal entry effects. In heat transfer analysis one usually applies the flow length average Nusselt number. Because of the small geometry of plastic plates, the liquid flow remains in the laminar flow regime. Average laminar flow Nusselt numbers are well documented in ref. [6]. The intermediate walls in the plate separate the liquid flow in the various channels. As a result of the poor thermal conductivity of plastic, these intermediate walls are close to adiabatic. The pertaining Nusselt number for this heat transfer situation should be used. For metal plates, with good thermal conductivity properties, these intermediate walls act as extra heat transfer surfaces. The Nusselt number of four heated walls should be taken, multiplied by two to incorporate the doubled effective heat transfer surface. In equations (3)(5) the factor two reckons with the presence of a condensate film on both sides of the plate. The boundary condition from equation (1) is

$$
T(x, z=0)=T_{\text {in }} .
$$

In order to obtain an equation describing $\delta(x, z)$ attention is paid to the condensate film.

In the momentum equation in the $x$-direction the inertia terms can be neglected, in ref. [2] it has been demonstrated that for Prandtl numbers $\operatorname{Pr}>1$ these terms may be neglected. The buoyancy force exerted by the vapour on the film can also be neglected, because usually $\rho_{v} / \rho_{\mathrm{c}}$ is small. The momentum equation in the $x$-direction is

$$
\eta_{\mathrm{c}} \frac{\partial^{2} u_{\mathrm{c}}}{\partial y^{2}}=-\rho_{\mathrm{c}} g
$$

where $\eta_{\mathrm{c}}$ and $\rho_{\mathrm{c}}$ stand for the viscosity and the density of the condensate, respectively. The boundary conditions on $u_{\mathrm{c}}$ are

$$
\begin{gathered}
u_{\mathrm{c}}(y=0)=0 \\
\frac{\partial u_{\mathrm{c}}}{\partial y}(y=\delta)=0 .
\end{gathered}
$$

In refs. $[4,5]$ it has been demonstrated that for small

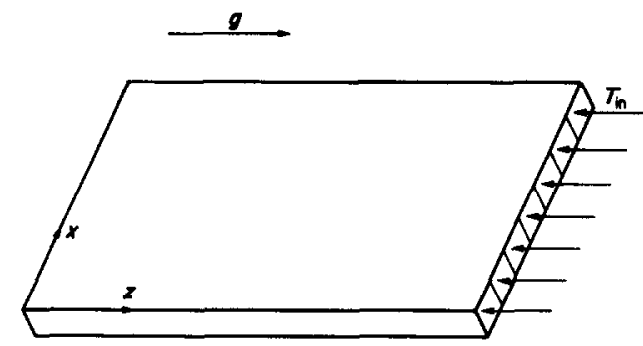

Fig. 3. Counter-current condensation process.

Kutateladze numbers the drag of the vapour on the film can be neglected, so the zero shear boundary condition is appropriate. Integration of equation (7) with respect to $y$ and the application of equations (8) and (9) yields

$$
u_{\mathrm{c}}(x, y, z)=\frac{g \rho_{\mathrm{c}}}{\eta_{\mathrm{c}}}\left(y \delta-\frac{1}{2} y^{2}\right) .
$$

Using the equation of conservation of mass, the velocity $v_{\mathrm{c}}(x, y, z)$ perpendicular to the plate can be determined as

$$
\frac{\partial v_{\mathrm{c}}}{\partial y}=\frac{-g \rho_{\mathrm{c}}}{\eta_{\mathrm{c}}}\left(y \frac{\partial \delta}{\partial x}\right)
$$

subject to the boundary condition

$$
v_{\mathrm{c}}(y=0)=0 .
$$

By integration of equation (11) with respect to $y$ and application of equation (12) one finds that

$$
v_{\mathrm{c}}(x, y, z)=\frac{-g \rho_{\mathrm{c}}}{2 \eta_{\mathrm{c}}} y^{2} \frac{\partial \delta}{\partial x} .
$$

The amount of condensate $\dot{m}$ passing through an infinite small area element $\mathrm{d} x$ at $y=\delta$, at both sides of the plate, is governed by

$$
\dot{m}=\left.2 \rho_{\mathrm{c}}\left(u_{\mathrm{c}} \frac{\partial \delta}{\partial x}-v_{\mathrm{c}}\right)\right|_{y=\delta} .
$$

Substitution of equations (10) and (13) into equation (14) produces

$$
\dot{m}=\frac{2 g \rho_{\mathrm{c}}^{2}}{\eta_{\mathrm{c}}} \delta^{2} \frac{\partial \delta}{\partial x}
$$

The amount of liberated heat is the product of the mass flow into the film and the latent heat $H_{\mathrm{fg}_{\mathrm{g}}}$ : this liberated latent heat is equal to the heat transported to the liquid

$$
\frac{2 g \rho_{\mathrm{c}}^{2} H_{\mathrm{fg}}}{\eta_{\mathrm{c}}} \delta^{2} \frac{\partial \delta}{\partial x}=h_{\mathrm{l}}\left(T_{\mathrm{sat}}-T\right)
$$

subject to the boundary condition

$$
\delta(x=0)=0 .
$$

The non-linear partial differential equations, equations (1) and (16), coupled by equations (2) and (3), and boundary conditions (6) and (17) represent the governing equations of the cross-current condensation process.

Next, the counter-current process is considered (Fig. 3). The equations describing this process can 
easily be derived from the equations of the crosscurrent process as

$$
\frac{-w_{1} c_{p 1}}{B} \frac{\mathrm{d} T}{\mathrm{~d} z}=h_{\mathrm{t}}\left(T_{\mathrm{sat}}-T\right)
$$

and

$$
\frac{2 g \rho_{\mathrm{c}}^{2} H_{\mathrm{fg}}}{\eta_{\mathrm{c}}} \delta^{2} \frac{\mathrm{d} \delta}{\mathrm{d} z}=h_{\mathrm{t}}\left(T_{\mathrm{sat}}-T\right) .
$$

Note that $T$ and $\delta$ are functions of $z$ only. The boundary conditions become

$$
T(z=L)=T_{\text {in }}
$$

and for equation (19)

$$
\delta(z=0)=0 .
$$

The equations describing the co-current process become (Fig. 4)

$$
\frac{w_{1} c_{p 1}}{B} \frac{\mathrm{d} T}{\mathrm{~d} z}=h_{\mathrm{t}}\left(T_{\mathrm{sat}}-T\right)
$$

and

$$
\frac{2 g \rho_{\mathrm{c}}^{2} H_{\mathrm{fg}}}{\eta_{\mathrm{c}}} \delta^{2} \frac{\mathrm{d} \delta}{\mathrm{d} z}=h_{\mathrm{t}}\left(T_{\mathrm{sat}}-T\right)
$$

with boundary conditions

$$
T(z=0)=T_{\text {in }}
$$

and

$$
\delta(z=0)=0 .
$$

In ref. [7] similar equations have been derived, and integrated numerically, for co- and counter-current condensation on a vertical circular tube. The analysis of these equations presented in the following sections can, therefore, right away be applied to both the aforesaid processes and the pertaining equations.

\section{SOLUTIONS IN CLOSED FORM}

In this section the previously derived differential equations will be set dimensionless and solved in closed form. Dimensionless variables and numbers are introduced and defined, and it will be demonstrated that two numbers entirely characterize the processes. The three configurations will be treated in a sequence opposite to that employed in the previous section.

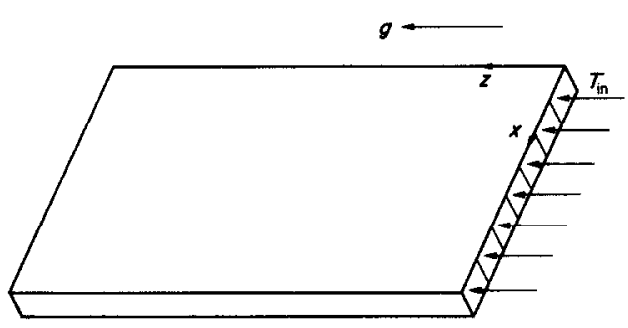

FIG. 4. Co-current condensation process

\section{Co-current process}

Equations (22) and (23), with application of equations (2) and (3), can be written in dimensionless form as

$$
\begin{gathered}
\frac{\mathrm{d} \Theta}{\mathrm{d} z}(1+\Delta)+N T U \Theta=0 \\
\Delta^{2}(1+\Delta) \frac{\mathrm{d} \Delta}{\mathrm{d} Z}-A d_{1} \Theta=0
\end{gathered}
$$

where

$$
\Theta=\frac{T_{\text {sat }}-T}{T_{\text {sat }}-T_{\text {in }}}
$$

$$
A d_{1}=\frac{h_{p 1}^{4} \eta_{\mathrm{c}} L\left(T_{\mathrm{sat}}-T_{\mathrm{in}}\right)}{16 g \rho_{\mathrm{c}}^{2} H_{\mathrm{fg}} k_{\mathrm{c}}^{3}}
$$

and with boundary conditions

$$
\begin{gathered}
\Theta(Z=0)=1 \\
\Delta(Z=0)=0 .
\end{gathered}
$$

The number of transfer units $N T U$ is inversely proportional to the liquid capacity flow through the plate and $A d_{1}$ is the ratio, to the fourth power, of the total heat transfer coefficient of the plate and the heat transfer coefficient of the condensate films.

By adding equations (26) and (27), integrating with respect to $Z$, and applying equations (34) and (35), the following relation for $\Delta$ and $\Theta$ can be obtained :

$$
\Theta=\frac{-N T U}{3 A d_{1}} \Delta^{3}+1 .
$$

Equation (36) is substituted in equation (26) and integrated to give

$$
\begin{array}{r}
\ln \left(p^{3}+1\right)-\left(\frac{3 A d_{1}}{N T U}\right)^{1 / 3}\{3 p-\ln (p+1) \\
\left.+\frac{1}{2} \ln \left(p^{2}-p+1\right)-\sqrt{3} \arctan \left(\frac{2}{\sqrt{3}} p-\frac{1}{\sqrt{ } 3}\right)\right\} \\
=-N T U Z+C_{1}
\end{array}
$$

where

$$
p=(\Theta-1)^{1 / 3} .
$$

By application of boundary condition (34) $C_{1}$ is obtained 


$$
C_{1}=-\frac{\pi}{6} \sqrt{3}\left(\frac{3 A d_{1}}{N T U}\right)^{1 / 3} .
$$

Values of $\Theta(Z=1)=\Theta_{\text {out }}$, and hence for the outlet temperature of the liquid, can be determined with equations (37)-(39) for any given $N T U$ and $A d_{1}$ by numerical iteration. Note that $1-\Theta_{\text {our }}$ represents what is sometimes called the heat exchanger effectiveness. The maximum possible exit temperature, $T(X=1)=T_{\text {sat }}$, corresponds with $\Theta_{\text {out }}=0$.

\section{Counter-current process}

Equations (18) and (19) of the counter-current process are set dimensionless by introducing equations (28)-(33)

$$
\begin{gathered}
\frac{\mathrm{d} \Theta}{\mathrm{d} Z}(1+\Delta)-N T U \Theta=0 \\
\Delta^{2}(1+\Delta) \frac{\mathrm{d} \Delta}{\mathrm{d} Z}-A d_{1} \Theta=0
\end{gathered}
$$

and equations (20) and (21) become

$$
\begin{gathered}
\Theta(Z=1)=1 \\
\Delta(Z=0)=0 .
\end{gathered}
$$

Equations (40) and (41) are added, then integrated with respect to $Z$, and equations (42) and (43) are applied, yielding

$$
\Theta=\frac{N T U}{3 A d_{1}} \Delta^{3}+\Theta(Z=0) .
$$

Using equation (44) to eliminate $\Delta$ in equation (40) and integrating the resulting equation with respect to $Z$ yields

$$
\begin{aligned}
\ln \left(q^{3}+1\right)+\left(\frac{3 A d_{1}}{N T U} \Theta(Z=0)\right)^{1 / 3} & \{3 q-\ln (q+1) \\
+\frac{1}{2} \ln \left(q^{2}-q+1\right)-\sqrt{3} \arctan & \left.\left(\frac{2}{\sqrt{3}} q-\frac{1}{\sqrt{3}}\right)\right\} \\
& =N T U Z+C_{2}
\end{aligned}
$$

where

$$
q=\left(\frac{\Theta}{\Theta(Z=0)}-1\right)^{1 / 3} .
$$

By substituting $\Theta(Z=0)$ into equation (45)

$$
C_{2}=\frac{\pi}{6} \sqrt{3}\left(\frac{3 A d_{1} \Theta(Z=0)}{N T U}\right)^{1 / 3}
$$

The unknown $\Theta(Z=0)=\Theta_{\text {out }}$ can be evaluated for any $N T U$ and $A d_{1}$, by numerical iteration of equations (45) $-(47)$.

\section{Cross-current process}

The cross-current equations, equations (1) and (16), are set dimensionless by equations (28)-(32) and

$$
X=\frac{x}{B}
$$

$$
A d_{2}=\frac{h_{p 1}^{4} \eta_{\mathrm{c}} B\left(T_{\mathrm{sat}}-T_{\mathrm{in}}\right)}{16 g \rho_{\mathrm{c}}^{2} H_{\mathrm{fg}} k_{\mathrm{c}}^{3}} .
$$

The number $A d_{2}$ has the same physical meaning as $A d_{1}$, but this McAdam number contains $B$ as the flowoff length. The equations become

$$
\begin{gathered}
\frac{\partial \Theta}{\partial Z}(1+\Delta)+N T U \Theta=0 \\
\Lambda^{2}(1+\Lambda) \frac{\partial \Delta}{\partial X}-A d_{2} \Theta=0 .
\end{gathered}
$$

The boundary conditions of these coupled partial differential equations are

$$
\begin{gathered}
\Theta(X, Z=0)=1 \\
\Delta(X=0, Z)=0 .
\end{gathered}
$$

To solve the above non-linear problem the following procedure will be employed. Instead of $\Theta(X, Z)$ the mean temperature $\Theta(X, Z)$ will be determined and defined as

$$
\Theta(X, Z)=\int_{0}^{x} \Theta(X, Z) \mathrm{d} X .
$$

Combining equations (51), (53) and (54) yields

$$
\bar{\Theta}=\frac{1}{3 A d_{2}} \Delta^{3}\left(1+{ }_{4}^{3} \Delta\right) .
$$

Integrating equation (50) with respect to $X$ and substitution of equation (54)

$$
\frac{\partial \bar{\Theta}}{\partial Z}=-N T U \int_{0}^{x} \frac{\Theta}{1+\Delta} \mathrm{d} X .
$$

Combining equations (51) and (56)

$$
3 A d_{2} \frac{\partial \bar{\Theta}}{\partial Z}=-N T U \Delta^{3}
$$

and equations (55) and (57) produce

$$
\left(\frac{1}{\Delta}+1\right) \partial \Delta=-\frac{N T U}{3} \partial Z
$$

Integrating equation (58)

$$
\ln \Delta+\Delta=\frac{-Z N T U}{3}+C_{3}(X) .
$$

The integration function $C_{3}(X)$ can be determined by combination of equations (51) and (52)

$$
\Delta^{3}(Z=0)\left(1+\frac{3}{4} \Delta(Z=0)\right)=3 A d_{2} X
$$

Equations (59) and (60) yield

$$
\ln \left(\frac{\Delta}{\Delta(Z=0)}\right)+\Delta-\Delta(Z=0)=\frac{-N T U Z}{3}
$$

For any $N T U$ and $A d_{2}$ it is possible to determine $\Theta(X=1, Z=1)=\Theta_{\text {out }}$ by successive numerical iteration of the analytically obtained equations (60) and (61), and relation (55). 


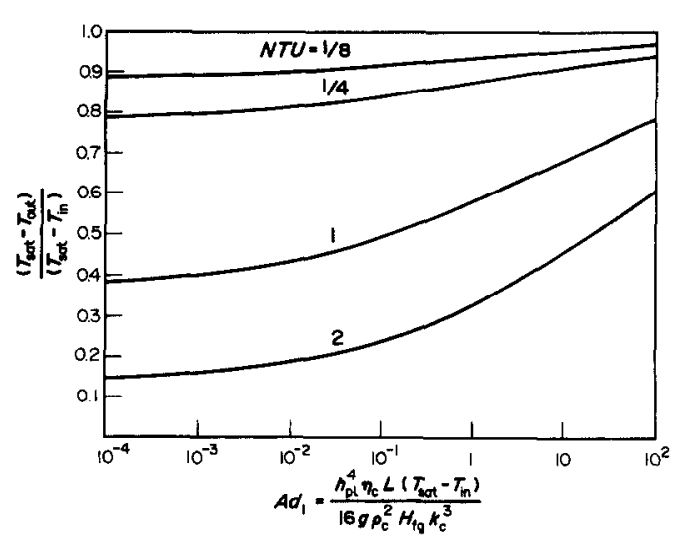

Fig. 5. Variation of $\left(T_{\text {sat }}-T_{\text {out }}\right) /\left(T_{\text {sat }}-T_{\text {in }}\right)$ with the McAdam number for the co-current process.

\section{Condensate production}

An important unknown is the amount of energy transferred and condensate produced per unit time. The simplest way to determine it is to employ an overall energy balance

$$
\dot{M} H_{\mathrm{fg}}=w_{1} c_{p 1}\left(T_{\text {out }}-T_{\text {in }}\right)
$$

where $\dot{M}$ represents the total mass flow of vapour to the film. This equation is set dimensionless by applying equations (28) and (32) and

$$
Q=\frac{\dot{M} H_{\mathrm{f}}}{B L h_{p l}\left(T_{\text {sat }}-T_{\text {in }}\right)} .
$$

Equation (62) becomes

$$
Q=\frac{\left(1-\Theta_{\text {out }}\right)}{N T U}
$$

Here, $\Theta_{\text {out }}$ follows from equations (37)-(39) for the co-current process, from equations (45)-(47) for the counter-current process, and from equations (55), (60) and (61) for the cross-current process.

\section{NUMERICAL EVALUATION}

In the previous sections the governing equations for the three relevant process configurations were formulated, nondimensionalized and solved. Implicit algebraic relations were obtained between $\Theta_{\text {out }}$, the numbers $N T U$ and $A d_{1}$ or $A d_{2}$. In this section results will be presented of numerical calculations of $\Theta_{\text {out }}$, performed on a Harris $\mathrm{H} 500$, for several values of $N T U$ and $A d_{1}$ or $A d_{2}$, employing Newton's iteration method. The iterations are stopped when the difference between two successive steps has become smaller than $10^{-6}$.

Values of $A d_{1}$ ranging between $10^{-4}$ and $10^{2}$ are substituted into equations (37) and (45), while $N T U$ is set equal to $2,1,0.25$ and 0.125 . These ranges of $N T U$ and $A d_{1}$ extend well beyond most current practical applications. In Figs. 5 and 6 the iterated $\Theta_{\text {out }}$ is plotted against $A d_{1}$, for the co- and countercurrent process, respectively. The exit temperatures of the counter-current process are somewhat higher than

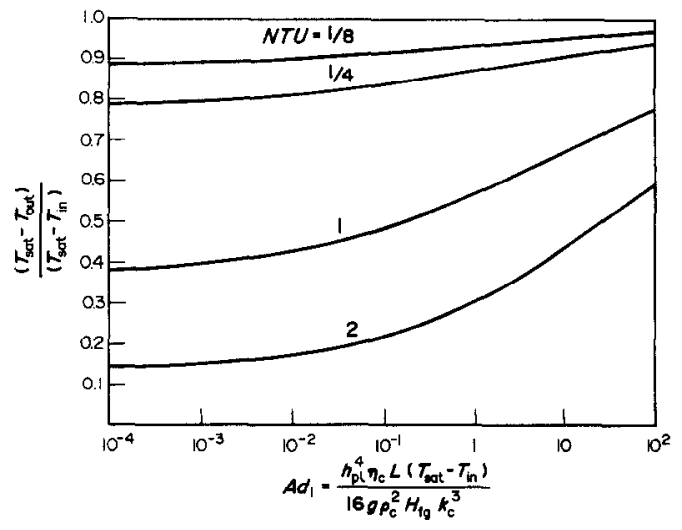

FIG. 6. Variation of $\left(T_{\text {sat }}-T_{\text {out }}\right) /\left(T_{\text {sat }}-T_{\text {in }}\right)$ with the McAdam number for the counter-current process.

the exit temperatures of the co-current process, in particular for high $N T U$, but the difference is very small. It should be borne in mind that a higher $\Theta_{\text {out }}$ implies a lower exit temperature, see equation (28).

To calculate $\Theta_{\text {out }}$ for the cross-current case, equations (60) and (61) are successively iterated after substituting values for $N T U=2,1,0.25$ and 0.125 , while $A d_{2}$ varies between $10^{-4}$ and $10^{2}$. In Fig. $7, \Theta_{\text {out }}$ is depicted against $A d_{2}$. It is striking that Figs. 5-7 almost coincide when $A d_{1}=A d_{2}$, that is when the length and width of the plate are equal. This implies that, if $L=B$, the orientation of the plate towards gravity is not important anymore.

Furthermore, it can be concluded that for values of $L / B>1$ (because of the application of channel plates this is often the case in plastic heat exchangers) crosscurrent condensation will lead to higher take-off temperatures of the liquid and higher condensate productions. This might be expected because the flow-off length of the condensate is shorter.

For reasons of brevity the dimensionless variable $A d$ is introduced, $A d$ stands for $A d_{1}$ for co- and counter-current condensation, see equation (33), and for $A d_{2}$ for cross-current condensation, see equation (49).

Next the exit temperatures for the three cases are calculated for $A d=10^{-4}, 10^{-2}, 1$ and $10^{2}$ while

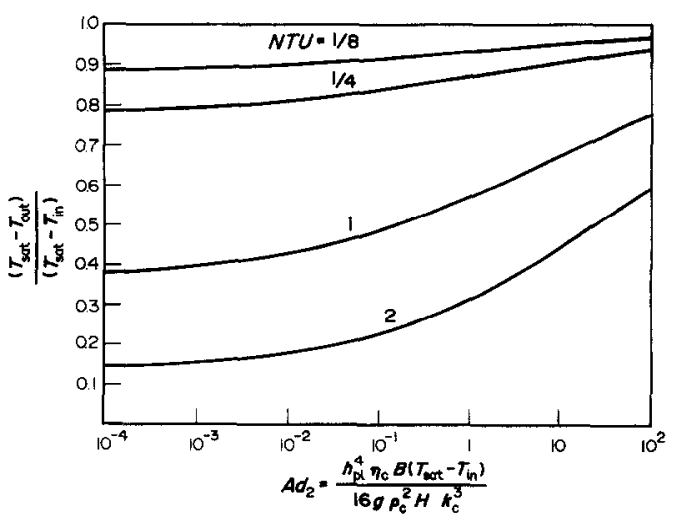

Fig. 7. Variation of $\left(T_{\text {sat }}-T_{\text {out }}\right) /\left(T_{\text {sat }}-T_{\text {in }}\right)$ with the McAdam number for the cross-current process. 


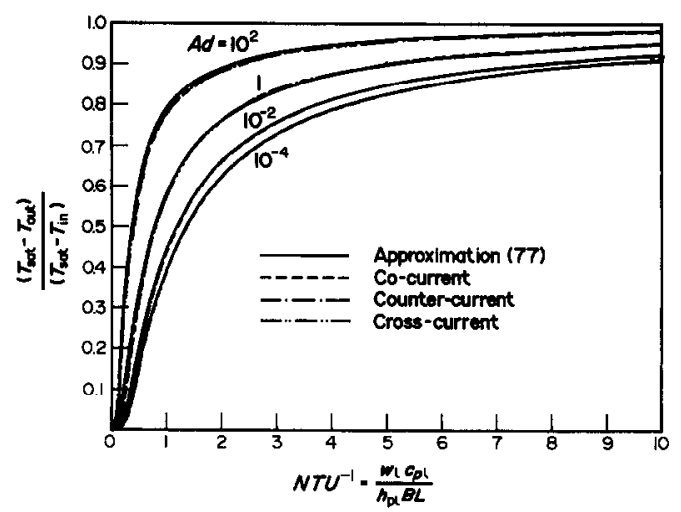

FIG. 8. Variation of $\left(T_{\text {sat }}-T_{\text {out }}\right) /\left(T_{\text {sat }}-T_{\text {in }}\right)$ with $N T U^{-1}$ for the co-, counter- and cross-current process and according to approximation (77).

$N T U^{-1}$ is varied between 0 and 10. In Fig. $8, \Theta_{\text {out }}$ is drawn vs $N T U^{-1}$. Again it is obvious that for $A d_{1}=A d_{2}$ the exit temperatures are almost the same. It also shows that the exit temperatures tend to zero, for all $A d$ 's, when the liquid flow is nearly zero. Hence, the exit temperatures are equal to $T_{\text {sat }}$, and decrease when the liquid flow increases.

Figure 8 confirms the expected trend with the exit temperatures for large $A d$ decreasing more strongly when the liquid flow increases. For large $A d$ the heat transfer resistance of the film is important when compared with that of the plate. So, when the liquid flow increases the thicker condensate film, for large $A d$, will considerably affect the exit temperature. For small $A d$, on the contrary, the thickness and heat transfer resistance of the condensate film are of minor importance, even when the liquid flow and condensate production increase.

In Fig. 9 the energy transfer $Q$ is plotted against $N T U^{-1}$. for the same values of $A d$ as is done in the previous figure, using equation (64). For small values of $N T U^{-1}$, increasing the liquid flow results in increasing condensation rates, although the exit temperature decreases. But a further increase of the flow, however, will not lead to any significant increase of the condensate production and energy transfer. Both

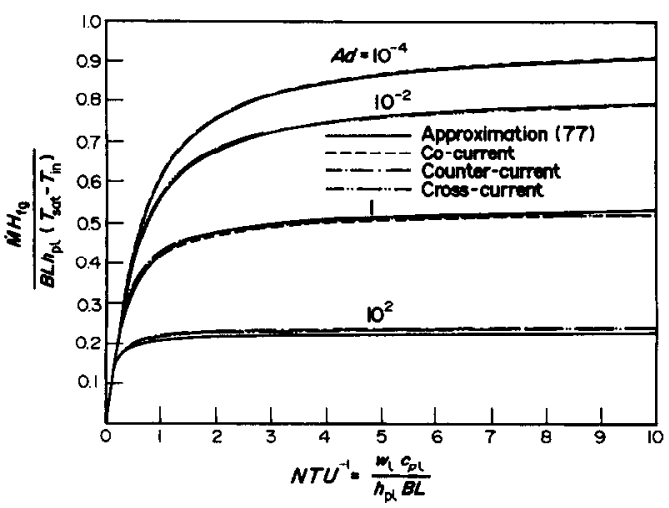

FIG. 9. Variation of $Q$ with $N T U^{-1}$ for the co-, counter- and cross-current process and according to equation (62) and approximation (77). the liquid flow and the plate area have to be increased to achieve higher condensate productions, see equations (32), (63) and (64).

\section{ASYMPTOTIC ANALYSIS}

When attention is paid to Figs. 5-7, the supposition arises that there are limiting values of $\Theta_{\text {out }}$ for large and small $A d$ 's. This supposition is examined in some detail for the cross-current process, using asymptotic methods [8, 9]. This analysis forms the basis of an approximate solution, which will be introduced at the end of this section.

Small values of $A d$ imply a poor heat transfer coefficient of the plate and a good heat transfer coefficient of the condensate, see equations (33) and (49), whereas the inverse is true of large values of $A d$. For intermediate $A d$ 's, the heat transfer coefficients of the plate and condensate film are of about the same magnitude.

For small values of $A d_{2}$, which may occur when steam condenses on a plastic channel plate, the following perturbation expansions can be applied :

$$
\begin{gathered}
\Theta(X, Z)=\Theta_{0}(X, Z)+O(\varepsilon) \\
\Delta(X, Z)=\varepsilon\left(\Delta_{0}(X, Z)+O(\varepsilon)\right)
\end{gathered}
$$

where

$$
\varepsilon=\left(3 A d_{2}\right)^{1 / 3} \text {. }
$$

Substituting equations (65)-(67) into equations (50) and (51), equating the coefficients of equal power of $\varepsilon$ and solving the resulting equations for the zeroorder terms yield

$$
\begin{gathered}
\Theta_{0}=\mathrm{e}^{-N T U Z} \\
\Delta_{0}=X^{1 / 3} \mathrm{e}^{-(Z N T U) / 3} .
\end{gathered}
$$

Applying equation (54) gives

$$
\Theta_{\text {out }}=\Theta_{0}(X=1, Z=1)=\mathrm{e}^{-N T U} \text {. }
$$

This zero-order solution suggests that for small $A d_{2}$ the heat transfer coefficient of the condensate film is negligibly large compared with the heat transfer coefficient $h_{\mathrm{pl}}$ of the channel plate. The film on the plate can be considered to be isothermal and its presence disregarded.

For large values of $A d_{2}$, e.g. when isopropanol or toluene condenses on a metal channel plate, the perturbation expansions

$$
\begin{gathered}
\Theta(X, Z)=\Theta_{0}(X, Z)+O(\varepsilon) \\
\Delta(X, Z)=\frac{1}{\varepsilon}\left(\Delta_{0}(X, Z)+O(\varepsilon)\right)
\end{gathered}
$$

where

$$
\varepsilon=\left(\frac{1}{3 A d_{2}}\right)^{1 / 4}
$$

can be applied. Equations (71)-(73) are substituted into equations (50) and (51). Equating coefficients of 
equal power of $\varepsilon$ and solving the resulting equations for the zero-order terms yield

$$
\begin{gathered}
\Theta_{0}=1 \\
\Delta_{0}=\left(\frac{4}{3} X\right)^{1 / 4} .
\end{gathered}
$$

Application of equation (54) gives

$$
\Theta_{\text {out }}=\bar{\Theta}_{0}(X=1, Z=1)=1 \text {. }
$$

The zero-order solutions (74) and (75) represent-in dimensionless form-the classical Nusselt type condensation on an isothermal plate with temperature $T_{\text {in }}$.

An analogous reflection of equations (26) and (27) from the co-current process, and equations (40) and (41) from the counter-current process, for large and small $A d_{1}$, yields the same limiting valucs for $\Theta_{\text {out }}$ and the same physical interpretations.

The drawn lines, plotted in Figs. 8 and 9, represent an approximate solution of the broken lines, which are calculated by iteration of the closed-form solutions. The approximate function is based on the knowledge of the asymptotic behaviour of $\Theta_{\text {out }}$ for large and small $A d$ 's, which is the same for the three processes, and Figs. 5-9 for intermediate $A d$ 's. This approximation of $\Theta_{\text {out }}$ is an explicit function of $N T U$ and $A d$

$$
\Theta_{\text {out }}=\left(\mathrm{e}^{-N T U}-1\right)\left(\frac{\mathrm{e}^{(N T U) / 2}}{(0.55 A d)^{0.3}+\mathrm{e}^{(N T U) / 2}}\right)+1 .
$$

Equation (77) tends to the limiting values of $\Theta_{\text {out }}$ for large and small $A d$ 's, and matches these values properly for intermediate $A d$ 's. Furthermore, $\Theta_{\text {out }}$ tends to zero when the liquid flow tends to zero, independent of $A d$, and tends to unity when the liquid flow tends to infinity. These physical properties are both essential to the processes and also satisfied by equation (77). The amount of condensate production can be evaluated with equation (64).

\section{CONCLUDING REMARKS}

Based on the assumption of Nusselt type condensation, which has been found to be consistent in the past for most of the vapours applied, an analysis has been carried out of the condensation processes on non-isothermal plates, Three configurations have been examined and compared: namely co-current, counter-current and cross-current condensation. The governing equations have been derived, analysed and solved. The major results obtained are given below.

(a) The process is governed by the McAdam number and the number of transfer units.

(b) For small liquid flows the exit temperature is equal to the saturation temperature, independent of Ad.

(c) For large and small $A d$ 's, the asymptotic behaviour of the three processes is equal.

(d) For square plates $(L=B)$, the take-off temperatures for all three situations are nearly the same, but if $L>B$ the cross-current condensation will result in higher take-off temperatures and condensation rates.

(e) For small values of $A d$, the condensate film can be considered isothermal.

(f) For large values of $A d$, the plate can be considered isothermal.

(g) At certain mass flows, dependent on $\boldsymbol{A d}$, a further increase in liquid flow will not result in increasing condensation rates. Only an increase in both plate area and liquid flow will result in higher condensate productions.

With knowledge of the asymptotic behaviour of the governing equations, there has been constructed an accurate and compact approximation function for the exit temperature, valid for all configurations of condensation.

Acknowledgements-The author wishes to express his gratitude to Messrs H. Korstanje, C. van de Beek and G. Vegt who cooperated in discussions.

\section{REFERENCES}

1. W. Nusselt, Die Oberflächenkondensation des Wasserdampfes, Z. Ver. Dt. Ing. 60, 541-546, 569-575 (1916).

2. E. M. Sparrow and J. L. Gregg, A boundary layer treatment of laminar-film condensation, Trans. Am. Soc. Mech. Engrs 81, 13-17 (1959).

3. W. M. Rohsenow, Heat transfer and temperature distribution in laminar-film condensation, Trans. Am. Soc Mech. Engrs 78, 1645-1648 (1956).

4. J. C. Y. Koh, E. M. Sparrow and J. P. Hartnett, The two phase boundary layer in laminar film condensation, Int. J. Heat Mass Transfer 2, 6982 (1961).

5. J. C. Y. Koh, On integral treatment of two phase boundary layer in film condensation, $J$. Heat Transfer $\mathbf{8 3}, 359$ 362 (1961).

6. R. K. Shah and A. L. London, Laminar flow forced convection in ducts. In Advances in Heat Transfer, Suppl. 1. Academic Press, New York (1978).

7. M. Faghri and E. M. Sparrow, Parallel-flow and counterflow condensation on an internally cooled vertical tube, Int. J. Heat Mass Transfer 23, 559-562 (1980).

8. A. Aziz and T. Y. Na, Perturbation Methods in Heat Transfer. Hemisphere, Washington, DC (1984).

9. M. van Dyke, Perturbation Methods in Fluid Mechanics. Parabolic Press, Stanford, California (1975). 


\title{
CONDENSATION EN FILM SUR DES PLAQUES VERTICALES NON ISOTHERMES
}

Résumé- On présente une étude analytique de la condensation d'une vapeur saturéc purc sur la plaque froide d'un canal, en incluant l'interaction entre le liquide réfrigérant, le condensat et la vapeur. Ces équations pour la condensation sont posées dans le cas des courants parallèles ou croisés, mises sous forme adimensionnelle et résolues analytiquement. Les expressions implicites obtenues sont évaluées numériquement par itération. Les résultats sur le transfert thermique par condensation sont obtenus pour un large domaine de variation des nombres sans dimension du phénomène : le nombre de McAdam et le nombre d'unités de transfert. En utilisant les méthodes asymptotiques, on obtient une expression approchée simple qui est utilisable pour les besoins de l'ingénieur.

\section{FILMKONDENSATION AN NICHT-ISOTHERMEN SENKRECHTEN PLATTEN}

Zusammenfassung - Es wird eine analytische Untersuchung der Kondensation eines reinen, gesättigten Dampfes an einer gekühlten Platte vorgestellt, die auch die Wechselwirkung zwischen Kühlfüssigkeit, Kondensat und Dampf beinhaltet. Die Bilanzgleichungen für Kondensation im Gleich-, Gegen- und Kreuzstrom werden abgeleitet, dimensionslos gemacht und in geschlossener Form gelöst. Die resultierenden impliziten Ausdrücke werden durch Iteration numerisch gelöst. Auf diese Weise erhält man für einen weiten Bereich der dimensionslosen Kennzahlen des Prozesses (McAdams-Zahl und $N T U$ ) Ergebnisse für den Wärmeübergang bei der Kondensation. Außerdem wird mit Hilfe asymptotischer Verfahren eine einfache Näherungsbeziehung abgeleitet, die für die praktische Anwendung geeignet ist.

\section{ПЛЕНОЧНАЯ КОНДЕНСАЦИЯ НА НЕИЗОТЕРМИЧЕСКИХ ВЕРТИКАЛЬНЫХ ПЛАСТИНАХ}

\begin{abstract}
Анпотаци-Аналитически исследована конденсация чнстого насьшенного пара на охлахденной гофрированной пластине с учетом взаимодействия мехду охлахдающей хидкостью, конденсатом и паром. Выведены, приведены к безразмерному виду и решены в замкнутой форме определяющие уравнения для случаев движения пара по направлению, против и поперек течения пленки конденсата. Конечные уравнения решаются методом итерации. Получены данные для теплопереноса при конденсации в широхом диапазоне безразмерных чисел, харахтеризующих этот процесс. При помоши асимптотических методов выведено простое приближенное выражение, пригодное для инженерных приложени
\end{abstract}

